\title{
Sex and gender in respiratory physiology
}

\author{
Antonella LoMauro $($ and Andrea Aliverti \\ Number 2 in the Series "Sex and gender in lung disease" \\ Edited by Jason Weatherald, Marc Humbert and Renata Riha
}

Dipartimento di Elettronica, Informazione e Bioingegneria, Politecnico di Milano, Milan, Italy.

Corresponding author: Antonella LoMauro (antonella.lomauro@polimi.it)

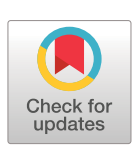

Copyight OThe authors 202

This version is distributed under the terms of the Creative Commons Attribution NonCommercial Licence 4.0. For commercial reproduction rights and permissions contact permissions@ersnet.org

This article has an editorial commentary: https://doi.org/10.1183/ 16000617.0217-2021

Received: 15 Feb 2021 Accepted: 8 June 2021

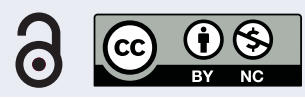

Shareable abstract (@ERSpublications)

Gender is a social concept. Sex is a biological concept that plays a role in respiratory physiology according to hormones and anatomy. Medicine is less evidence-based for women, while transsexual people represent new challenges for the clinicians. https://bit.ly/3wErYoY

Cite this article as: LoMauro A, Aliverti A. Sex and gender in respiratory physiology. Eur Respir Rev 2021; 30: 210038 [DOI: 10.1183/16000617.0038-2021].

\section{Abstract}

Sex is a biological concept determined at conception. Gender is a social concept. Medicine recognises sex as a biological variable and recommends including sex as a factor in clinical practice norms and as a topic of bench and clinical research. Sex plays a role in respiratory physiology according to two pathways: hormones and anatomy, with females characterised by smaller dimensions at every level of the respiratory system. Sex hormones also play specific roles in lung inflammatory processes, breathing control and in response to diseases. The literature is extremely controversial because many factors need to be considered to avoid erroneous comparisons. The main difficulty lies in creating homogeneous groups of subjects according to age, body weight, lung/airway size, fluctuations in circulating hormone levels, and exercise protocol. Because almost all of the knowledge available in physiology is based on research in males, medicine for women is therefore less evidence-based than that being applied to men. Finally, the number of transsexual people is increasing and they represent new challenges for clinicians, due to the anatomical and physiological changes that they undergo.

\section{Introduction}

The terms sex and gender are often wrongly used interchangeably, while they refer to different topics and do complement each other [1, 2]. Sex is a biological concept. Gender is a social concept. Sex refers to anatomical and biological differences between females and males. The genitalia are referred to as primary sex characteristics. They are determined at the moment of conception, they develop in the womb, and then throughout childhood and adolescence. The secondary sex characteristics stem from the hormonal differences between the two sexes that develop during puberty. For better or worse, these basic biological differences affect people's perceptions of what it means to be female or male in any society. Gender refers to the social and cultural differences a society expects in people's behaviour, role and attitude based on their biological sex. Gender is a social construct that varies from society to society. Gender is selfidentified by the person, being a woman, a man, a girl or a boy, as well as in relationships with each other. In contrast to sex, gender is a fluid concept that can change over time [1, 2].

Transgender people are people whose gender identity differs from their physiological sex. Transsexual is the most specific and suitable term/adjective for people who have undergone sex change. Sex change implies transgender hormone therapy (or cross-sex hormone therapy or gender-confirming hormone therapy) and ultimately sex reassignment surgery. In gender-confirming hormone therapy, sex hormones and other hormonal medications are administered for the purpose of more closely aligning transgender individuals' secondary sexual characteristics with their gender identity. However, male and female sex hormones also play specific roles in lung inflammatory processes and therefore in response to diseases. Indeed, several lung function parameters vary throughout the menstrual cycle phases and during 
pregnancy. In addition, sex is shown to affect breathing control and susceptibility to some respiratory diseases [3]. For these reasons, transsexuality is likely to play a more of a role in respiratory physiology than transgenderism because of the hormonal intervention in the process.

In 2001, the Institute of Medicine recognised sex as a biological variable and not just as an observational feature [4]. The institute recommended including sex as a factor in clinical practice norms and as a topic of bench and clinical research. These recommendations ended up in an article in the journal Nature entitled "Putting gender on the agenda" [5].

In addition to hormones, sex plays a role in respiratory physiology according to another pathway: anatomy, with women being generally characterised as having smaller dimensions. This feature occurs at every anatomical level of the respiratory system, from the upper airways to the lungs. These inherent anatomical sex differences of the respiratory system appear in utero and continue throughout the human life span. However, some of these sex-based anatomical differences disappear after normalising data according to height or lung volume [6-10].

There is a tendency to ignore females in all areas of science, including physiology, with female subjects remaining seriously under-represented in clinical cohorts. Almost all knowledge available in physiology is based on research in males, with the inevitable exception of studies related to menstrual cycle, menopause and maternity [5]. Sociocultural factors have undoubtedly contributed to this result, according to the controversial consideration of the issues related to the role of women in society, including the scientific field; not to mention the poor basic monitoring of female participation in clinical trials [11]. If biomedical research keeps using many more male subjects in both animal and human studies, this will unintendedly short-change women's health care. "Medicine as it is currently applied to women is less evidence-based than that being applied to men” [5].

However, the female hormonal system is so complex, compared to the male one, that it is a crucial bias for the homogeneity of the group to be investigated and to minimise variability due to the oestrogen cycle.

Sociocultural factors of women's respiratory disease

One of the most striking examples of the impact of sociocultural factors in women's respiratory disease is COPD. Traditionally a male disease, COPD has rapidly increased more in women than in men in the last few years [12]. Such increased female COPD prevalence is believed to be due to women's changing smoking patterns (i.e. taking on more traditional male occupations) and significant sex-based differences in the disease [13]. After adjusting for the amount of tobacco smoked, women experience a greater rate of lung function decline than men $[14,15]$. Two hypotheses are proposed to explain this phenomenon: 1) the relatively smaller size of women's lungs, which implies that each cigarette smoked represents a higher "dose" compared to men; and 2) the different female metabolism of several components of tobacco smoke, which could translate into relatively higher and more prolonged exposure to toxic substances [16]. It is important to underline that sex differences occur not only in the metabolism of toxic substances in tobacco smoke, but also in the inflammatory response. Indeed, tobacco smoke may downregulate the expression of those genes involved with regulation of immune function [17, 18]. These adverse effects of tobacco smoking on inflammation may be reversible following smoking cessation [19]. In contrast, nicotine alone may have paradoxical anti-inflammatory properties by attenuating proinflammatory cytokines [18]. The biological parameters that influence the pharmacokinetics and metabolism of nicotine differ between males and females, with the latter metabolising nicotine at a higher rate because of ovarian hormones, specifically oestrogen. Female smokers report diminished subjective nicotine effects during the luteal phase (when progesterone is relatively higher than oestrogen) compared to the follicular phase (high oestrogen, low progesterone, figure 1) [20]. While males have a greater subjective nicotine sensitivity, female smokers are more sensitive to the non-nicotine-conditioned stimuli associated with cigarette smoking [21]. This might be the reason for women experiencing greater difficulty with smoking cessation than men [22]. Despite men starting tobacco use at a younger age and reporting greater nicotine use [23], women have a higher risk of developing tobacco-related morbidity and mortality [24].

More recently, it has been proposed that also differences between men and women in thoraco-abdominal inhalation patterns during smoking may also play a role [25]. Many stressors can impact sex disparities in lung development and lung disease. These comprise indoor and outdoor air pollution, anxiety, stress associated with socioeconomic status, access to health care, genetics, epigenetics, and diet [26]. Because of their domestic roles, women are particularly exposed to household air pollution, being one particularly relevant global environmental exposure. Household air pollution results from indoor burning of solid fuels for cooking and heating. Because households in poor countries typically have limited access to fuels, 


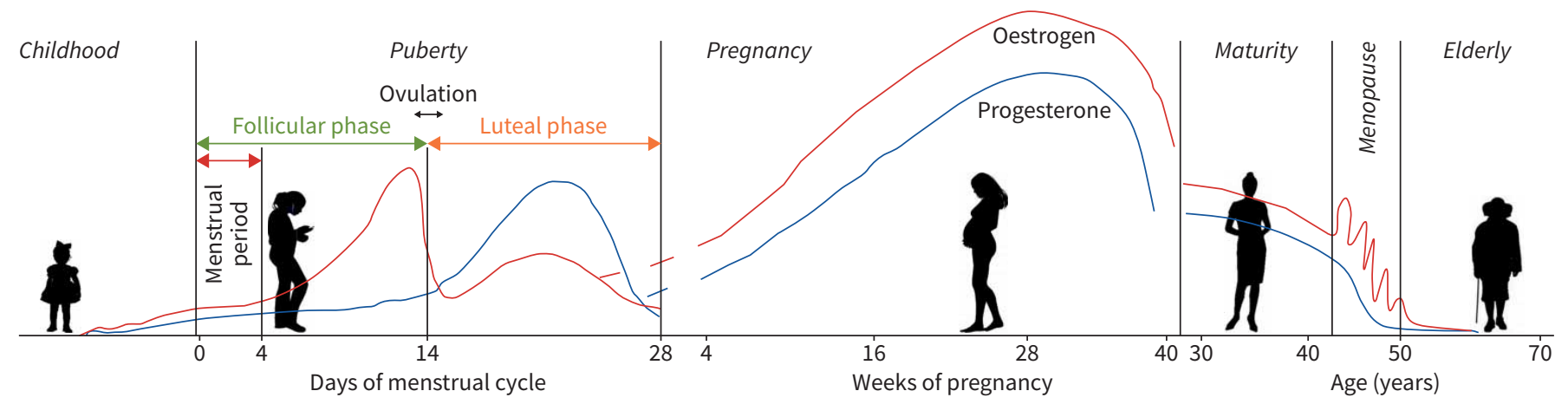

FIGURE 1 Summary of hormonal changes over the life cycle of women.

wood, charcoal, animal dung, coal or crop residues are then used for cooking on open fires or traditional unvented stoves. These systems have low combustion efficiencies, resulting in excessive emissions. Household air pollution is associated with approximately 4 million deaths each year, mainly women and children, secondary to COPD, cardiovascular diseases, acute pneumonia in children under age 5 years and lung cancer $[27,28]$.

Low socioeconomic status (i.e. educational level, occupational status and income) is inversely related to health status and mortality rate, including pulmonary disease. In the Hordaland County Cohort Study, low socioeconomic status was shown to be associated with increased lung function decline, particularly in men who meet the largest decline in forced vital capacity (FVC). In females, socioeconomic status seems to weakly affect lung function decline, while marital status is more important, with widows and married females having larger lung function decline than unmarried ones [29].

\section{Sex hormones}

Although this is a respiratory review, it is imperative to include a simple and general section dedicated to gonadal hormones. Sex-specific mechanisms of lung inflammation and the contributions of sex hormones to these mechanisms are evident from both clinical studies and experimental mouse models [30].

Sex hormones exert their actions via nuclear and membrane receptors [31]. Sex hormones are also capable of changing not only membrane fluidity, but also the expression of mitochondrial proteins and genes that mediate many cellular mechanisms [32, 33].

The hypothalamic-pituitary-gonadal (HPG) and hypothalamic-pituitary-adrenal (HPA) axes The HPG axis includes the hypothalamus, the pituitary gland and the gonads, and it ultimately produces the sex hormones, namely oestrogen, progesterone, testosterone, activin, inhibin and follistatin [34].

The hypothalamus releases the gonadotropin-releasing hormone $(\mathrm{GnRH})$ that targets the pituitary gland to release luteinising and follicle-stimulating hormones. The luteinising and follicle-stimulating hormones stimulate the gonads to produce sex hormones [35].

When the function of this axis is changed, the altered hormonal production not only affects reproduction, but it can also cause local and systemic effects in different systems, including the respiratory (or immune) system. Sex steroid hormone receptors, together with $\mathrm{GnRH}$, luteinising hormone and activin receptors have been identified in many tissues including the lung. This suggests that alterations in serum hormones would potentially affect lung function [36].

The neuroendocrine HPA axis, external to the HPG axis, also regulates lung diseases through the known roles of glucocorticoids in mediating the mechanisms of lung development and inflammation [37]. More research is needed to elucidate the mechanisms linking the physiological crosstalk between neuroendocrine and pulmonary systems, being influenced by the hormones secreted by both the HPG and HPA axes [38]. It must be mentioned that, besides the gonads, sex hormones can be synthesised locally by the lung. The lung also mediates local production of reactive oxygen species and/or undergoes oxidative stress, thereby contributing to inflammation. 
Sex hormone receptors in the lung

The receptors of male and female sex hormones are the oestrogen receptors, the androgen receptor and the progesterone receptors. The interaction between sex hormones and their corresponding receptors has both genomic and nongenomic effects. The former includes control of transcription through binding of hormone-receptor complexes to gene-promoter regions. The latter consists of indirect regulation, with transcriptional action, through activation of intracellular signalling cascades mediated by $\mathrm{G}$ proteins [39, 40].

\section{Oestrogen}

Unfortunately, the literature on the effects of oestrogen on lung function and disease is inconclusive, presumably because of the pleiotropic expression of the oestrogen receptors together with the multiple genomic and non-genomic effects of oestrogen in various cells. The studies have suggested that oestrogens potentially influence the outcomes of developmental, inflammatory and disease processes by influencing cytokines and inflammatory mediators in the lung through both up-regulation (interleukin (IL)-1 $\beta$, IL-6, type I interferon (IFN), tumour necrosis factor (TNF)- $\alpha$, NF- $\kappa B$ and toll-like receptor 8) and down-regulation/inhibition (transforming growth factor (TGF)- $\beta 1$ and IL-10) [41-43].

\section{Progesterone}

The regulatory effects of progesterone have been marginally researched. It seems that progesterone makes the contractility and the relaxation of bronchial smooth muscle respectively decrease and increase [44]. Progesterone has the most powerful vasodilator effect on pulmonary arteries in both male and female rats [45]. In humans, it is positively associated with peak expiratory flow rate during the luteal phase of the menstrual cycle. Progesterone receptors are expressed in the fibrotic areas in the case of usual interstitial pneumonia. The influence of progesterone on cytokines and inflammatory mediators in the lung is also in terms of both up-regulation (IL-10, IL-1 $\beta$, IL-5, IL-6, IL-22, TNF- $\alpha$, IL-4, Src/p21, Erk, IL-9 and IL-13) and down-regulation/inhibition (NF-kB, TGF- $\beta 1$, connective tissue growth factor, transgelin, plasminogen activator inhibitor-1 and IFN- $\gamma)[46,47]$.

\section{Testosterone}

Testosterone is generally proposed to have protective roles because it seems to cause bronchial tissue relaxation, to reduce the response to histamine and to attenuate airway inflammation [48-50]. In addition, testosterone influences cytokines and inflammatory mediators in the lung through an up- (IL-2, IFN- $\gamma$, haemoglobin subunit (Hbb)-b1, Hbb-y and haemoglobin subunit theta 1) and a down-regulation (IL-33, thymic stromal lymphopoietin, IL-4, IL-5, IL-13, angiopoietin-like 4 and cytochrome P450, family 1, subfamily A, polypeptide 1) [51-54].

\section{Sex hormones and lung immune cells}

Ongoing investigations reveal that sex hormones can affect airway tone and inflammation, and exert effects in different lung cell types, like alveolar macrophages, neutrophils, dendritic cells and eosinophils, but this goes beyond the purpose of the present article [30, 38].

\section{Sex differences in respiratory system structure and function}

Sex-related differences start in utero and persist throughout the life span (figure 2). Starting from the 26th week of gestation, a female fetus is generally characterised by being $\sim 1.5$ weeks ahead in lung maturation and phospholipid profiles, reflecting surfactant production and maturation. At birth, female lungs are more responsive to hormone accelerators of surfactant production. However, female lungs are smaller, presumably because of fewer respiratory bronchioles, but not of the number of alveoli per unit area [7, 30, 55-57]. During childhood and adolescence, dysanapsis occurs. The concept of dysanapsis refers to a disproportionate growth pattern between the parts that constitute an organ in the presence of the normal physiological function of the whole [58]. Indeed, in puberty and beyond, female airways and lung parenchyma grow proportionally, whereas in males the growth of airway lags behind the growth of the lung. Boys therefore exhibit disproportionately fewer alveoli for the number of airways, resulting in lower expiratory flow rate, even when somatic growth has ceased [59-61]. This suggests that larger male lungs would have longer conducting airways, being disadvantageous during expiration. During adolescence, higher respiratory pressures generated by males are attributed to the influence of testosterone and to the changing shape of the thorax and respiratory muscles during puberty [62]. Because sex-induced dysanaptic growth of airways versus lungs is maintained in adulthood, women should be placed at an advantage in terms of respiratory mechanics and airflow [7, 10]. Indeed, females have a higher ratio of forced expiratory volume in one second $\left(\mathrm{FEV}_{1}\right)$ and FVC [62]. Finally, it is physiological to lose lung function with age, independently of disease pathology. The elastic recoil of the lung, the elastic recoil of the large airways and the alveolar air volume decrease with age, while the relative amount of connective tissue in the lungs 


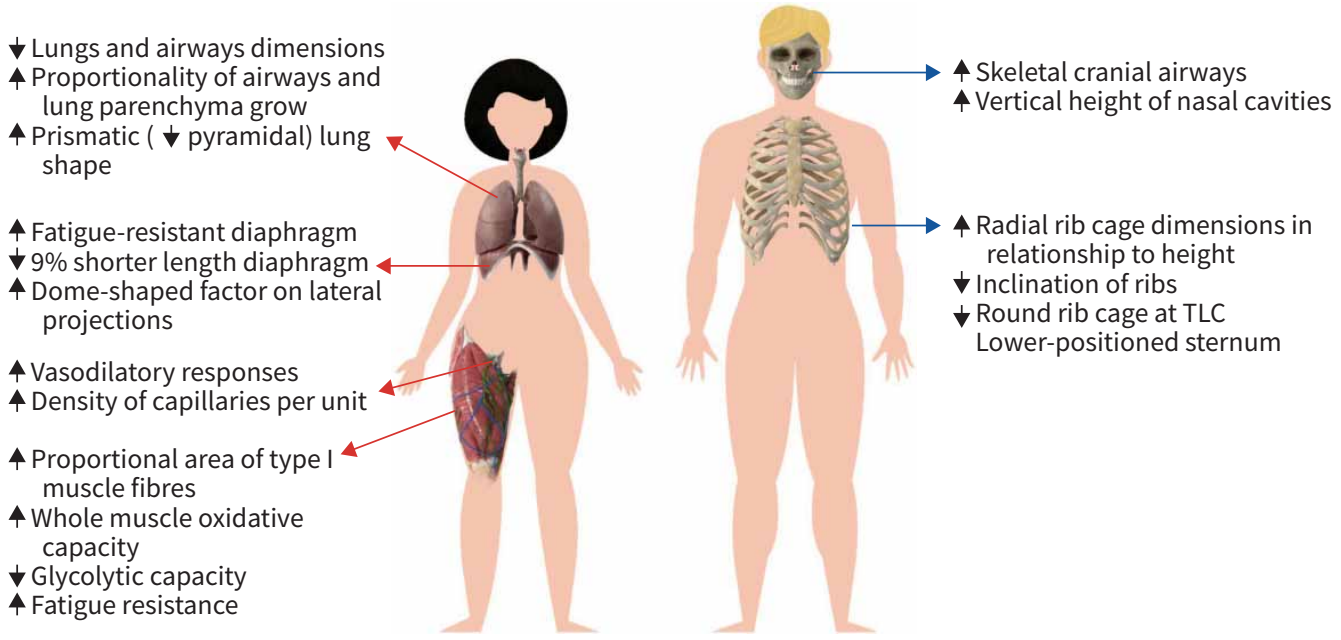

FIGURE 2 A simplified conceptual model to summarise the main sex differences in lung, airways, ribcage and skeletal muscles. $\downarrow$ : lower than the other sex; $\uparrow$ : higher than the other sex. TLC: total lung capacity.

increases. However, these age-related changes in the mechanical properties of the lungs develop later and proceed more slowly in women [6]. Males lose elastic recoil of their larger airways more than women [63].

Supported by the European Respiratory Society, the European Respiratory Society Global Lung Function Initiative (GLI) has developed sex-specific reference equations, with age and height being independent and significant predictors, for spirometry [64], carbon monoxide transfer factor [65] and static lung volumes [66]. It is interesting to notice that the authors never comment on differences induced by sex. They "just" derive equations for males and females, taken for granted that sex is an essential parameter that influences reference ranges for lung volumes and transfer factor.

We strongly recommend referring to the European Respiratory Society GLI when male and female trends are to be considered for lung volumes and carbon monoxide transfer factor.

The GLI network is now the largest resource for reference values for routine lung function testing and the GLI equations are quickly becoming the gold standard for lung function outcomes. GLI equations summarise data using flexible statistical methods, therefore allowing a non-linear relationship to be described across all ages, while defining the normal values of a wide range of ages as well as a more accurate lower limit of normal [67].

The importance of these hormonal, anatomical, structural and functional differences lies in sex differences in diseases. Although pathophysiology is not the purpose of this article, we take the example of asthma to underline the complex, fascinating and often unknown relation among these actors. Female proportional growth between airways and lungs results in lower specific airway resistance, making females less susceptible to some respiratory diseases, like asthma. However, asthma displays a notorious sexual dimorphism across the lifespan, with symptoms in children being more prevalent in boys, while in adult populations asthma is more frequently reported in women $[68,69]$. An epidemiological study has shown that, in the US, prepubertal boys have more asthma, with an incidence of $9.2 \%$ compared to $7.4 \%$ of girls under 18 years old. However, this pattern is reversed after puberty, with the asthma prevalence rate for women (10.4\%) being almost twice that for men (6.2\%) [70]. The hypothesis is that hormonal changes, which start in puberty, contribute to asthma development. This suggests an important involvement of female sex hormones in mediating these effects. This hypothesis is supported by asthma symptoms and hospitalisation rates varying throughout the menstrual cycle [71], by a decline in asthma incidence in women after menopause [72, 73], and by the severity of asthma increasing in men during the fifth or sixth decade of age when testosterone levels decrease, suggesting a potential role of androgens in mediating asthma pathophysiology [74]. Indeed, premenstrual asthmatic deterioration is reported by $46 \%$ of female patients [75], presumably because of an abnormal hormonal control of $\beta_{2}$-adrenoceptors. Although exogenous progesterone produces paradoxical downregulation and desensitisation of $\beta_{2}$-adrenoceptors in asthmatic but not in non-asthmatic women, the oral combined contraceptive pill does not alter $\beta_{2}$-adrenoceptor regulation in stable asthmatic females [76]. 
The control of breathing and sex hormones

The ultimate goal of breathing is guaranteeing optimal oxygen $\left(\mathrm{O}_{2}\right)$ intake, to support aerobic metabolism and carbon dioxide $\left(\mathrm{CO}_{2}\right)$ removal, to maintain the acid-base balance. The respiratory drive dynamically modulates this gas exchange according to the demands of the body. Three components control the respiratory drive: 1) the central medullary rhythm/pontine pattern generator and integrator; 2) the sensory inputs to the integrator; and 3) the motor output to the respiratory muscles [3, 77-79]. Chemoreceptors are specialised cells capable of detecting changes in the partial pressures of carbon dioxide, of oxygen or $\mathrm{pH}$ in the fluid around them. Central chemoreceptors, sensitive to changes in $\mathrm{CO}_{2} / \mathrm{pH}$, are widespread throughout the brain at different sites (namely, the retrotrapezoid nucleus, nucleus of the solitary tract, locus coeruleus, caudal medullary raphe, fastigial nucleus of the cerebellum and lateral hypothalamus). Interestingly, these sites also possess broadly distributed sex hormone receptors and therefore they could possibly modulate breathing [80]. The two main peripheral chemoreceptors, that also control breathing, are 1) the carotid bodies and 2) the aortic bodies. The former is located in the common carotid artery bifurcation. They principally monitor circulatory $\mathrm{O}_{2}$ content and project their information via the carotid sinus branch of the glossopharyngeal nerve. The aortic bodies are located near the arch of the aorta, sensitive to partial arterial $\mathrm{O}_{2}$ pressure, arterial $\mathrm{CO}_{2}$ partial pressure and $\mathrm{pH}$ changes. Their information is projected via the carotid sinus branch of the vagus nerve. Both peripheral chemoreceptors input to the dorsal medullary nucleus of the solitary tract. In the carotid bodies, sex hormone receptors for progesterone and oestradiol are also present [81].

Sex can influence breathing control via different pathways by influencing the central integrator as well as the sensory inputs and via motor output to the respiratory muscles. For example, oestrogen and androgen receptors are present in the hypoglossal and phrenic nuclei in male and female rats [82]; while genioglossus electromyographic activity significantly increases after hormone therapy in healthy postmenopausal women. This confirms an important effect of female hormones on pharyngeal dilator muscle activity. The authors hypothesise progesterone to be responsible for the aforementioned substantial and significant impact found in electromyographic activity. The authors also speculate that this hormonal influence might render the female airway less collapsible, therefore protecting women from obstructive sleep apnoea [83]. Gonadal hormones were first associated with ventilation in 1904 [84]. The regulation of respiration varies according to many factors, but it is so complex that the literature is controversial on the role of sex. Most of the studies indicate that, under baseline conditions, women tend to ventilate less than men [85-88]. However, other data report minute ventilation $\left(V_{\mathrm{E}}^{\prime}\right)$ to be higher in women [89, 90], similar between the two sexes [91-93] or ventilatory differences to disappear after correcting data for body surface area [94]. These conflicting results could be related to the study design, to the instrumentation used and to the difficulty of recruiting a homogeneous group of subjects in terms of age, body mass and sex. In addition to these factors, menstrual/oestrous cycle stages and hormonal concentrations of the participants also play a role. For example, progesterone is known to act as a respiratory stimulant [79] in both males and females [95, 96]. In a feline model, extra intravenous administration of progesterone makes phrenic nerve activity increase in both sexes. However, the response is much more variable in female cats, and this is possibly due to the hormonal fluctuations of their oestrous cycle [97]. The effects of progesterone on ventilation seem to be potentiated by oestradiol [98] and by increasing the number of progesterone receptors. However, oestradiol supplementation demonstrates conflicting results in its effect on ventilation in both rats and humans [99-102]. The different methods, numbers of subjects or species are not the only factors that can explain such great variability. The doses of hormones used also contribute importantly. When physiological doses of progesterone and oestradiol are used, no difference is observed, while changes occur predominantly when the levels of these hormones are in the supra-physiological range. Therefore, the results coming from a hormonal dosage higher than normal physiological range should be interpreted with scepticism or with caution [3].

Finally, elevated plasma concentrations of testosterone are known to impact respiratory parameters [103], with testosterone administration in hypogonadal males resulting in increasing $V_{E}^{\prime}$ [104]. Similar results occur after injecting higher doses of testosterone that exceed the upper limit of the physiological range [105], with no apparent effect in the case of low dosage [106]. The effect of testosterone on ventilation therefore seems to also depend on the doses used. Finally, testosterone has been suggested to impact breathing regulation after being converted to oestradiol by aromatase [107].

Interestingly, low levels of dehydroepiandrosterone sulphate (DHEA-S), a key precursor of androgens and oestrogens in the peripheral tissue, are associated with impaired lung function in women (reduced FVC and $\mathrm{FEV}_{1} / \mathrm{FVC}$ ratio). Because women with low DHEA-S levels have a three-fold greater risk of developing airflow limitation, this supports the thesis of the beneficial effect of DHEA-S on women's respiratory health. A similar relationship in men has not yet been investigated. Future studies should aim to 
evaluate if restoring DHEA-S to normal levels effectively improves respiratory function, therefore decreasing the risk of airflow limitation [108].

Menstrual cycle and menopause

Hormonal factors and respiratory health in women are complex issues and still poorly understood and, in most aspects, poorly investigated, with the literature often being contradictory and confusing. One of the reasons for the complexity is endogenous hormones that vary according to factors directly related to reproduction, namely menarche, menstrual cycle (and its regularity), pregnancy, lactation and proximity to the menopause. Not forgetting the potential roles that contraceptive and exogenous hormone replacement therapy have in the lung health of women [109].

The menstrual cycle influences women's ventilatory pattern according to its different phases, probably due, at least in part, to the stimulatory effects of progesterone and oestrogen on the ventilatory drive.

According to sex hormones fluctuations, the human menstrual cycle is divided into: 1) the follicular phase, from the first day of menstruation to ovulation when progesterone is low while oestrogen reaches both its lowest (until the end of menstrual) and its peak (during ovulation) concentrations; and 2) the luteal phase, from ovulation to the first day of the menstrual period. The oestrogen level progressively reduces after ovulation, but it still increases in the middle of the luteal phase to remain high until reaching its lowest concentration during menses. The progesterone level increases after ovulation to its peak in the middle of the luteal phase, followed by a gradual decrease until menstruation (figure 1) [110, 111].

During resting conditions, most studies on the menstrual cycle report breathing to be higher in the luteal phase, in terms of increased $V^{\prime}{ }_{\mathrm{E}}$ and $V^{\prime}{ }_{\mathrm{E}} / \mathrm{CO}_{2}$ production [111-115], particularly when sex hormones increase [116]. However, there are few studies also reporting lack of significant luteal to follicular phase ratio differences in $V_{\mathrm{E}}^{\prime}$ during baseline conditions [86, 94].

Long or irregular menstrual cycles (oligomenorrhoea) are associated with reduced lung function (in terms of reduced FVC) and allergic asthma, independent of body mass index and physical activity. This suggests that airway pathology may also have a metabolic component in addition to a hormonal one [71].

The menopausal transition includes a plethora of hormonal and metabolic changes comprising ovarian function decline and fertility disappearance with endogenous oestrogen levels being first elevated and then declining (figure 1) [117]. Women during the perimenopausal transition become more insulin-resistant [118], with all the additional associated side effects.

Although the literature is still limited, there is a general consensus, based on different population-based longitudinal surveys carried out on wide samples [119-121], that menopause is associated with lower lung function and more respiratory symptoms. Menopause is associated with accelerated lung function decline, beyond the expected age change. In detail, when compared with women menstruating regularly, FVC decreases by $10.2 \mathrm{~mL} \cdot$ year $^{-1}$ in transitional women and by $12.5 \mathrm{~mL} \cdot$ year $^{-1}$ in post-menopausal women [122]. Early menopause seems to have a protective effect on airflow obstruction. A $15 \%$ lower risk of airflow obstruction is found in women with early ( $<45$ years) compared to normal ( $45-55$ years) menopause. However, early menopause is also associated with a $13 \%$ higher risk of lung restriction. Future research is needed to explain this result [119]

Clinicians should be aware that the menopausal transition puts women at risk of accelerated lung function decline. Thanks to the increased life expectancy, women will spend a greater proportion of their lifetime in the postmenopausal state. Hormone replacement therapy is more often used to try to contrast the side effects arising from menopause. However, hormone replacement therapy is associated with an increased risk for asthma, wheeze and hay fever [123], with an important interaction of body mass index. Lean women who are hormone replacement therapy users have a risk for asthma as high as overweight women not taking the therapy [124]. Because women's susceptibility to pulmonary diseases varies due to age and to the corresponding variation of oestrogen, it is hypothesised that this depends on mechanisms associated with cellular senescence that may be triggered by telomere shortening. Telomere shortening occurs at a slower rate in women compared to men [125].

\section{Pregnancy}

Sex steroids play an essential role in maintaining a normal pregnancy, as they participate in the control of a wide range of both maternal and placental functions as well as in the normal development and maturation of fetal organs including lungs and adrenal glands [126]. 
In humans, maternal and fetal adrenals produce androstenedione, dehydroepiandrosterone and DHEA-S, which are the pre-eminent circulating C19 steroid precursors for the synthesis of active sex hormones. The placenta is the primary endocrine organ for maintaining pregnancy and fetal growth as it produces oestradiol. All the released hormones, including androgens, oestrogens and progestogens, occur at extremely high concentrations in the maternal circulation by advancing gestation (figure 1).

Male sex differentiation occurs for the testosterone secretion by fetal testes, which begins around 8 weeks of human pregnancy, to become high between 10 and 17 weeks of gestation. The maximal fetal male-to-female ratio in testosterone serum levels occurs between 12-18 weeks of pregnancy, while after 24 weeks these levels are low in both sexes.

This means that the male lung is exposed to higher levels of testosterone (than females) in the period preceding the surge of surfactant synthesis. The surge of surfactant production occurs at mid-late gestation, when both sexes are exposed to increasing levels of oestradiol. For this reason, the surge of surfactant production is delayed in males and it is linked to androgen levels [127].

The combination of hormonal changes and increase in intra-abdominal uterine volume has, respectively, a chemical and a mechanical impact on respiratory functioning. The dyspnoea experienced in the first trimester of pregnancy, by more than half women, is hormonally mediated since the gravid uterus has limited dimensions. Indeed, progesterone has a direct stimulant effect on the respiratory centre [128, 129]. The early dyspnoea experienced by some pregnant women is probably caused by an excessive increase in sensitivity to carbon dioxide or hypoxia. The mechanism by which the chemoreceptors of these women respond more intensely to similar hormonal changes still needs to be elucidated [130].

The serum concentration of progesterone, which passes from $25 \mathrm{ng} \cdot \mathrm{mL}^{-1}$ at 6 weeks of gestation to $150 \mathrm{ng} \cdot \mathrm{mL}^{-1}$ at 37 weeks of gestation, correlates with hyperventilation during pregnancy [128, 130-132].

On the other hand, the progressively increased levels of progesterone and relaxin [133] induce collagen loss. The consequent relaxation of ligaments and cartilage, combined with the cranial mechanical action of the enlarging uterus, induces important adaptations at different levels of the chest wall (summarised in figure 3). The ribcage changes in shape, by means of an upward bucket handle shift centred around the xiphoidal process, but not in volume so that the lung is not restricted. Breathing becomes less thoracic, presumably because ribcage muscles are put in mechanical disadvantage for such ribcage geometrical adaptation. The ribcage also experiences a reduction of its height in order to accommodate space for the abdominal expansion. While abdominal muscles lengthen with pregnancy, the diaphragm is subjected to a length-adaptive mechanism and/or a conditioning effect to preserve it from pregnancy-induced changes in a way to have an active role during parturition. Despite the stretching effect of the uterus, which should have a thinning effect on the diaphragm, the thickness of the diaphragm is unchanged at the end of pregnancy. This might be associated with an increased resting thickness, if measured at the samelength. Because the uterus represents an increasing mechanical load for the diaphragm, the unchanged thickness at the end of pregnancy may indicate a conditioning effect of the uterus to prepare the diaphragm for the expulsive phase of labour [132].

Despite the geometric differences of female diaphragm (i.e. shorter length and greater dome-shape factor on lateral projections) when compared to males [134], conflicting results are reported on its fatigability. Two studies report the diaphragm to be more fatigue-resistant in women [135, 136], therefore supporting its abovementioned role during parturition [132]. A recent study, however, shows that diaphragm fatigue is greater in women compared to men in acute hypoxia, while no difference is found in normoxia [137]. These conflicting results may be due to the different stressors (exercise versus hypoxia) considered. These studies indicate that sex differences should also be investigated in terms of respiratory muscle fatigue [138].

\section{Transgender/transsexual patients: new challenges for clinical treatment}

The number of transgender people is increasing together with the number of gender re-assignment procedures being performed. Just to provide some numbers, 200 000-500000 transgender people currently live in the UK, while 3256 transsexual patients underwent surgical procedures in 2016 as reported by the American Society of Plastic Surgery [139, 140]. Unfortunately, the literature on transgender/transsexual subjects is scant or absent. Call for further research is mandatory. Due to the anatomical and physiological changes that they may undergo, these patients represent unexpected challenges for the clinicians. For example, the use of transgender hormone therapy may have physiological and pharmacological consequences, like possible interactions with anaesthetic drugs. In addition, exogenous oestrogens may significantly increase the risk of venous-thromboembolism in male-to-female 


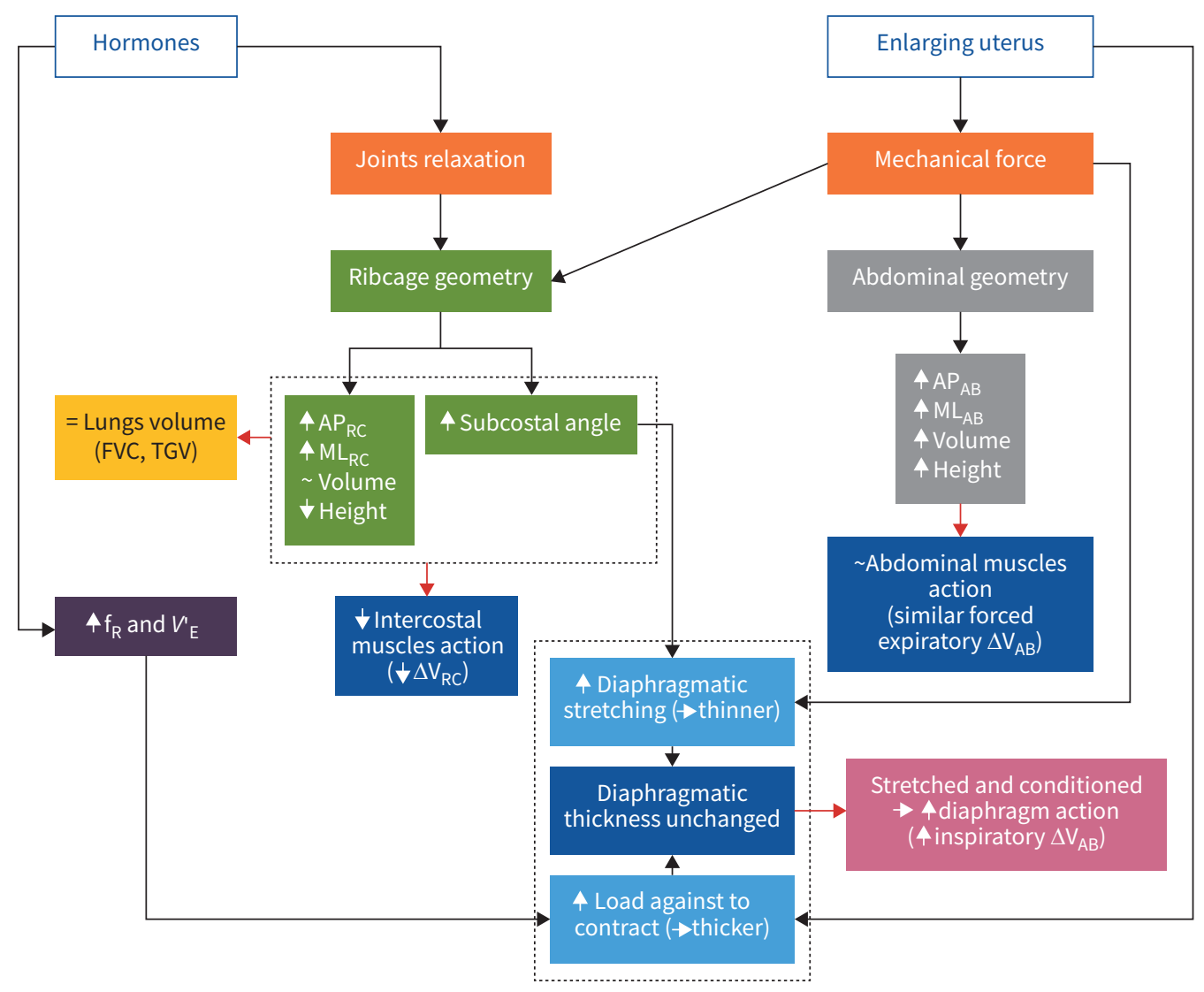

FIGURE 3 Schematic diagram summarising the generalised effects of pregnancy and their interactions on the respiratory system. FVC: forced vital capacity; TGV: total gas volume; $\mathrm{AP}_{\mathrm{RC}}$ : antero-posterior diameter at xiphoidal process; $\mathrm{ML}_{\mathrm{RC}}$ : medio-lateral diameter at xiphoidal process; $\Delta \mathrm{V}_{\mathrm{RC}}$ : ribcage contribution to breathing; $V_{E}^{\prime}$ : minute ventilation; $\mathrm{f}_{\mathrm{R}}$ : respiratory frequency; $\mathrm{AP}_{\mathrm{AB}}$ : antero-posterior diameter at umbilical level; $\mathrm{ML}_{\mathrm{AB}}$ : medio-lateral diameter at umbilical level; $\Delta \mathrm{V}_{\mathrm{AB}}$ : abdominal contribution to breathing; $\uparrow$ : increment; $\downarrow$ : decrement.

transition. Cross-sex hormone therapy is reported to have a controversial role in obstructive sleep apnoea. Three patients (two woman-to-male transgender subjects) experienced changes in their obstructive sleep apnoea status after gender-confirming hormone therapy [141]. Although men are more prone to develop obstructive sleep apnoea because of their anatomical facial features (i.e. longer upper airway and larger soft palate, figure 2) [10, 142], it is extremely unlikely that women assigned female gender at birth exposed to transgender hormone therapy with androgens develop an anatomically male upper airway [143]. The role of cross-sex hormone therapy needs to be investigated. Up to now, there is only one ongoing study on masculinising testosterone treatment and its effects on preclinical cardiovascular disease, muscle strength and power, aggression, physical fitness, and respiratory function in transgender men [144]. While longing to read these results, we also wish for similar studies for transgender women.

Transgender patients also undergo a wide spectrum of gender-confirming surgical procedures with important anatomical considerations. These procedures comprise plastic, reconstructive, urologic and gynaecological surgery. The main question is whether these interventions impact the inborn anatomical sex differences. While gender-affirming hormone therapy cannot influence these intrinsic sex-related anatomical features, surgery sometimes does. For example, breast surgery (either augmentation or reduction) does not change the shape of the lungs, being more pyramidal in male [145], and of the ribcage, with men's ribs being more horizontally oriented [146]. By contrast, procedures involving the shape of the face, of the jaw and of the airways might have important implications for mask ventilation and tracheal intubation [139]. Finally, Haynes and Stumbo [9] showed how the use of non-birth sex influences the interpretation of spirometry data, therefore placing these patients at risk for misdiagnosis (either over diagnosis or under diagnosis of lung disease) and, consequently, inappropriate treatment. When using non-birth sex, predicted FVC and $\mathrm{FEV}_{1}$ become significantly higher or lower in subjects born males or 
$\downarrow$ Airways dimensions $\downarrow$ Lung dimensions $\downarrow$ Alveoli

4 Prismatic lung shape

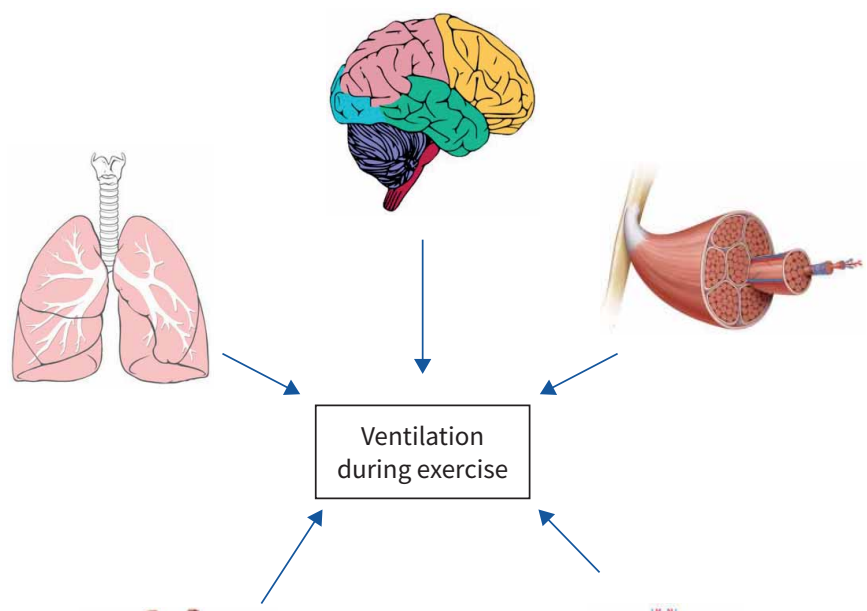

Skeletal muscles

4 Oxidation of fat

$\downarrow$ Oxidation for carbohydrate and amino acids

$\uparrow$ Oxygen uptake kinetics during moderate exercise intensities

4 Whole muscle oxidative capacity

$\downarrow$ Glycolytic capacity

4 Fatigue resistance during exercise

4 Density of capillaries per unit of skeletal muscles
Respiratory muscles

4 Absolute oxygen uptake at peak exercise

$\downarrow$ Efficiency of breathing

4 Fraction use of cardiac output

4 Recruitment of extra-diaphragmatic accessory muscles

4 Mechanical work of breathing
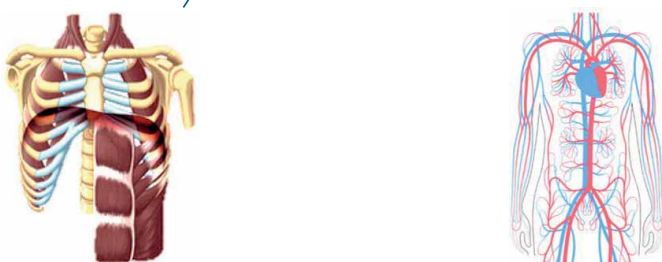

$\checkmark$ Oxygen delivery to the working muscle

4 Vasodilatory responses of skeletal muscles

4 Muscle perfusion

FIGURE 4 Summary of the sex differences within the key physiological systems implicated in ventilation during maximal exercise performance. Data refer to females. $\downarrow$ : lower; $\uparrow$ : higher.

females, respectively. The authors raise important ethical issues. Although their study provides scientific evidence that birth sex, rather than gender, must be considered in the prediction equations, patients may feel their gender identity to be violated if birth sex is used. They propose to follow a so-called two-step approach [9], recommended by lesbian, gay, bisexual and trans (LGBT) advocates [147, 148]. There are two possible ways to conduct spirometric tests without violating a patient's right to gender identity while respecting physiologic accuracy. The first is to also include gender identity, together with birth sex, in the demographic profile recorded in pulmonary function systems as well as in the electronic medical records. The second is to create transgender predicted equations by simply using birth sex but linked to the patient's gender identity in the existing equation [9].

A new emerging and controversial medical, legal and ethical issue, which is arising nowadays, is how to accommodate transgender athletes [149-151]. While there are still many unsolved questions about sex influencing the ventilatory pattern at rest, questions about sex differences in the physiological response to exercise are even more difficult to answer. This is because sex differences cover almost all of the key physiological systems implicated in exercise performance, namely supraspinal neurons, motoneurons, respiratory system, circulatory system and skeletal muscles. Figure 4 summarises the sex differences of the main impacts of the key physiological systems on ventilation during maximal exercise performance, which will be elucidated in more detail in another article in this series on cisgender. When it comes to transgender athletes, things become more complicated because of a potential conflict with fairness. This conflict arises because physiology suggests that transwomen have an advantage over their cisgender counterpart, because of relatively higher testosterone levels and prior male physiology. Conversely, transmen athletes may be disadvantaged in comparison with cismen [152, 153].

According to the International Olympic Committee, a transgender woman may be eligible to compete in the female category if her total serum testosterone levels are suppressed below $10 \mathrm{nmol} \cdot \mathrm{L}^{-1}$ for at least 12 months prior to and during competition [154]. Indeed, two recent systematic reviews report hormone therapy in transwomen to decrease muscle cross-sectional area, lean body mass, strength and haemoglobin levels. However, only haemoglobin decreases to similar levels seen in cisgender women after 4 months of hormone therapy, while the other values remain higher than those in cisgender women even after 12-36 months of hormone therapy. The authors therefore conclude that "it is possible that transwomen competing 


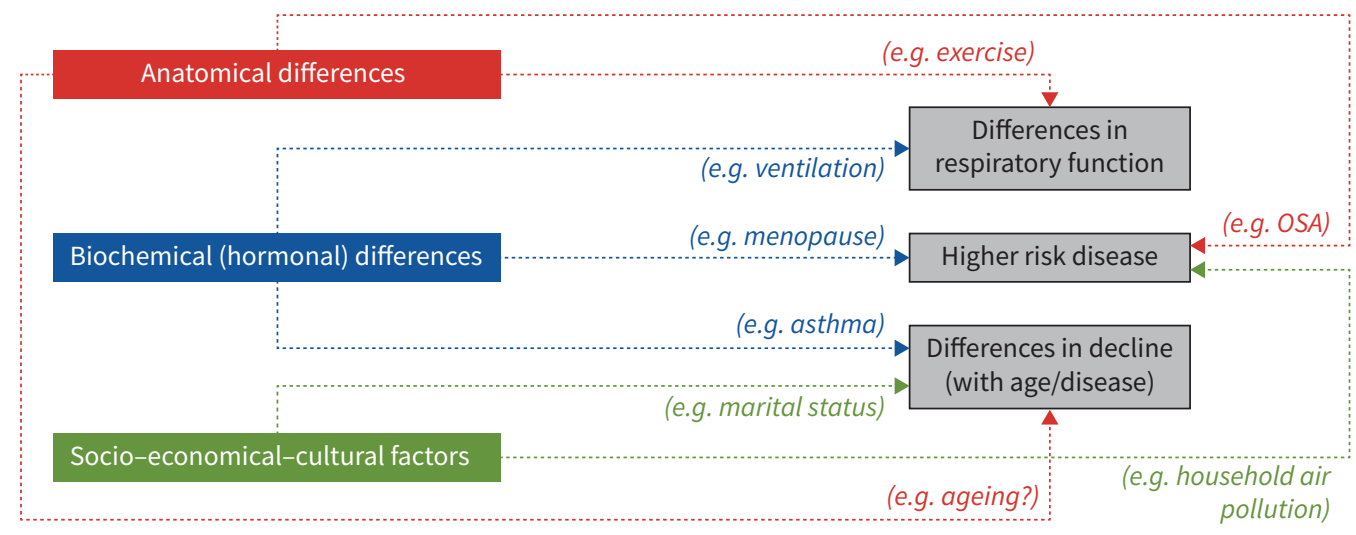

FIGURE 5 Schematic diagram of the possible impact of anatomical, hormonal, socio, economic and cultural factors on sex-related differences in respiratory function and decline as well as disease risk. OSA: obstructive sleep apnoea.

in sports may retain strength advantages over cisgender women, even after 3 years of hormone therapy" [153, 155]. Hence, while inclusion supports transsexual athletes competing in the division that matches their gender identity, this may not satisfy the principle of fairness [152]. This evidence is relevant for policies regarding the participation of transgender athletes in sports and competitions.

\section{Conclusions}

The clinical and functional significance of sex differences in respiratory physiology lies in both anatomical and hormonal features, with also socio-economical-cultural factors playing a role (figure 5). The literature is extremely controversial because many factors should be considered in order to avoid erroneous comparisons. The main difficulty is creating homogeneous groups of subjects according to age, race, body weight, lung/airway size, fluctuations in circulating hormone levels and exercise protocol. In addition, the presented results come from both animal and human studies and sometimes the variable of interest is not the main outcome of the studies.

Sex differences exist. They start from the very beginning, in utero, in terms of both anatomy and physiology, to extend later in terms of sociocultural, legal and economical factors. Differences that exist throughout the whole life span and for which geographical placement plays a crucial role. In most cases, and definitely more often, such sex differences are unfavourable to women. The recent election of the first woman Vice-President of the United States is a victory for all those women who were and still are enslaved, outcasted, exploited, emarginated and underpaid just for being born women. However, this is just one step of a long journey in which women must study and "be studied" more. The best solution comes from another "first" woman, Marie Curie, the first woman to win a Nobel Prize as well as the first person - man or woman - to win the prestigious award twice:

"Nothing in life is to be feared, it is only to be understood. Now is the time to understand more, so that we may fear less.”

Provenance: Commissioned article, peer reviewed.

Previous articles in this series: No. 1: Cheron C, McBride SA, Antigny F, et al. Sex and gender in pulmonary arterial hypertension. Eur Respir Rev 2021; 30: 200330.

Conflict of interest: A. LoMauro has nothing to disclose. A. Aliverti has nothing to disclose.

\section{References}

1 World Health Organization (WHO). Gender and health. https://www.who.int/health-topics/gender\#tab=tab_1

2 Bewley S, McCartney M, Meads C, et al. Sex, gender, and medical data. BMJ 2021; 372: n735.

3 Gargaglioni LH, Marques DA, Patrone LGA. Sex differences in breathing. Comp Biochem Physiol A Mol Integr Physiol 2019; 238: 110543. 
4

Exploring the Biological Contributions to Human Health: Does Sex Matter? Washington, National Academy Press, 2001.

$5 \quad$ Putting gender on the agenda. Nature 2010; 465: 665

6 Becklake MR, Kauffmann F. Gender differences in airway behaviour over the human life span. Thorax 1999; 54: 1119-1138.

7 LoMauro A, Aliverti A. Sex differences in respiratory function. Breathe 2018; 14: 131-140.

8 Carey MA, Card JW, Voltz JW, et al. It's all about sex: gender, lung development and lung disease. Trends Endocrinol Metab 2007; 18: 308-313.

9 Haynes JM, Stumbo RW. The impact of using non-birth sex on the interpretation of spirometry data in subjects with air-flow obstruction. Respir Care 2018; 63: 215-218.

10 LoMauro A, Aliboni L, Aliverti A. Sex differences in the anatomy of the airways and the lungs: impact on dysanapsis across the lifespan. In: Silveyra P, Tigno XT, eds. Sex-Based Differences in Lung Physiology, Berlin/Heidelberg, Springer, 2021; pp. 13-38.

11 Ballantyne A, Rogers W. Gender agenda: Let's track women's trial participation. Nature 2010; $465: 1005$.

12 American Lung Association. Taking her breath away: the rise of COPD in women. 2013. https://lundquist.org/ news/taking-her-breath-away-rise-of-copd-women

13 Aryal S, Diaz-Guzman E, Mannino DM. Influence of sex on chronic obstructive pulmonary disease risk and treatment outcomes. Int J Chron Obstruct Pulmon Dis 2014; 9: 1145-1154.

14 Bjornson W, Rand C, Connett JE, et al. Gender differences in smoking cessation after 3 years in the Lung Health Study. Am J Public Health 1995; 85: 223-230.

15 Gan WQ, Man SFP, Postma DS, et al. Female smokers beyond the perimenopausal period are at increased risk of chronic pulmonary disease: A systematic review and meta-analysis. Respir Res 2006; 7: 52.

Uppstad $\mathrm{H}$, Osnes $\mathrm{GH}$, Cole KJ, et al. Sex differences in susceptibility to PAHs is an intrinsic property of human lung adenocarcinoma cells. Lung Cancer 2011; 71: 264-270.

17 Spira A, Beane JE, Shah V, et al. Airway epithelial gene expression in the diagnostic evaluation of smokers with suspect lung cancer. Nat Med 2007; 13: 361-366.

18 Ashare RL, Wetherill RR. The intersection of sex differences, tobacco use, and inflammation: implications for psychiatric disorders. Curr Psychiatry Rep 2018; 1: 75.

19 King CC, Piper ME, Gepner AD, et al. Longitudinal impact of smoking and smoking cessation on inflammatory markers of cardiovascular disease risk. Arterioscler Thromb Vasc Biol 2017; 37: 374-379.

DeVito EE, Herman AI, Waters AJ, et al. Subjective, physiological, and cognitive responses to intravenous nicotine: Effects of sex and menstrual cycle phase. Neuropsychopharmacology 2014; 39: 1431-1440.

21 Perkins KA. Sex differences in nicotine reinforcement and reward: Influences on the persistence of tobacco smoking. Nebr Symp Motiv 2009; 55: 143-169.

22 Smith $\mathrm{PH}$, Bessette AJ, Weinberger $\mathrm{AH}$, et al. Sex/gender differences in smoking cessation: A review. Prev Med 2016; 92: 135-140.

23 Substance Abuse and Mental Health Services Administration. Key Substance Use and Mental Health Indicators in the United States: Results From the 2016 National Survey on Drug Use and Health (HHS Publication No. SMA 17-5044, NSDUH Series H- 52). Rockville, MD, Center for Behavioral Health Statistics and Quality, Substance Abuse and Mental Health Services Administration, 2021.

24 Allen AM, Oncken C, Hatsukami D. Women and smoking: the effect of gender on the epidemiology, health effects, and cessation of smoking. Curr Addict Rep 2014; 1: 53-60.

Polverino M, Capuozzo A, Cicchitto G, et al. Smoking pattern in men and women: A possible contributor to sex differences in smoke-related lung diseases. Am J Respir Crit Care Med 2020; 202: 1048-1051.

Silveyra P, Al Housseiny H, Rebuli M. Sex and gender differences in the susceptibility to environmental exposures. In: Silveyra P, Tigno XT, eds. Sex-Based Differences in Lung Physiology, Berlin/Heidelberg, Springer, 2021; pp. 251-290.

Lim SS, Vos T, Flaxman AD, et al. A comparative risk assessment of burden of disease and injury attributable to 67 risk factors and risk factor clusters in 21 regions, 1990-2010: A systematic analysis for the Global Burden of Disease Study 2010. Lancet 2012; 380: 2224-2260.

28 World Health Organization (WHO), Global Health Observatory (GHO). Population using solid fuels (estimates): data by country. 2014. https://www.who.int/data/gho/indicator-metadata-registry/imr-details/318

29 Johannessen A, Eagan TML, Omenaas ER, et al. Socioeconomic risk factors for lung function decline in a general population. Eur Respir J 2010; 36: 480-487.

30 Townsend EA, Miller VM, Prakash YS. Sex differences and sex steroids in lung health and disease. Endocr Rev 2012; 33: 1-47.

31 Hansberg-Pastor V, González-Arenas A, Piña-Medina AG, et al. Sex hormones regulate cytoskeletal proteins involved in brain plasticity. Front Psych 2015; 6: 165

32 Capllonch-Amer G, Llado I, Proenza AM, et al. Opposite effects of 17- $\beta$ estradiol and testosterone on mitochondrial biogenesis and adiponectin synthesis in white adipocytes. J Mol Endocrinol 2013; 52: $203-214$. 
Klinge CM. Estrogenic control of mitochondrial function and biogenesis. J Cell Biochem 2008; 105: 1342-1351.

Meethal SV, Atwood CS. The role of hypothalamic-pituitary-gonadal hormones in the normal structure and functioning of the brain. Cell Mol Life Sci 2005; 62: 257-270.

Millar RP, Lu ZL, Pawson AJ, et al. Gonadotropin-releasing hormone receptors. Endocr Rev 2004; 25: 235-275.

Atwood CS, Bowen RL. A multi-hit endocrine model of intrinsic adult-onset asthma. Ageing Res Rev 2008; 7 : 114-125.

Malenka R, Nestler E, Hyman S. Chapter 10: Neural and Neuroendocrine Control of the Internal Milieu. In: Sydor A, Brown R, eds. Molecular Neuropharmacology: A Foundation for Clinical Neuroscience. 2nd edn. New York, McGraw-Hill Medical, 2009; pp. 246-259.

Fuentes N, Silveyra P. Endocrine regulation of lung disease and inflammation. Exp Biol Med 2018; 243 1313-1322.

Filardo EJ, Thomas P. Minireview: G protein-coupled estrogen receptor-1, GPER-1: Its mechanism of action and role in female reproductive cancer, renal and vascular physiology. Endocrinology 2012; 153: 2953-2962.

Stowikowski BK, Lianeri M, Jagodziński PP. Exploring estrogenic activity in lung cancer. Mol Biol Rep 2017; 44: 35-50.

Smith LC, Moreno S, Robertson L, et al. Transforming growth factor beta1 targets estrogen receptor signaling in bronchial epithelial cells. Respir Res 2018; 19: 160.

Kovats S. Estrogen receptors regulate innate immune cells and signaling pathways. Cell Immunol 2015; 294: 63-69.

Shim B, Pacheco-Rodriguez G, Kato J, et al. Sex-specific lung diseases: Effect of oestrogen on cultured cells and in animal models. Eur Respir Rev 2013; 22: 302-311.

Perusquía M, Hernández R, Montaño LM, et al. Inhibitory effect of sex steroids on guinea-pig airway smooth muscle contractions. Comp Biochem Physiol C Pharmacol Toxicol Endocrinol 1997; 118: 5-10.

English KM, Jones RD, Jones TH, et al. Gender differences in the vasomotor effects of different steroid hormones in rat pulmonary and coronary arteries. Horm Metab Res 2001; 33: 645-652.

Migliaccio A, Piccolo D, Castoria G, et al. Activation of the Src/p21(ras)/Erk pathway by progesterone receptor via cross-talk with estrogen receptor. EMBO J 1998; 17: 2008-2018.

Kunzmann S, Ottensmeier B, Speer CP, et al. Effect of progesterone on Smad signaling and TGF- $\beta$ / Smad-regulated genes in lung epithelial cells. PLoS One 2018; 13: e0200661.

Verma MK, Miki Y, Sasano H. Sex steroid receptors in human lung diseases. J Steroid Biochem Mol Biol 2011; 127: 216-222.

Fu L, Freishtat RJ, Gordish-Dressman H, et al. Natural progression of childhood asthma symptoms and strong influence of sex and puberty. Ann Am Thorac Soc 2014; 11: 898-907.

Kouloumenta V, Hatziefthimiou A, Paraskeva E, et al. Non-genomic effect of testosterone on airway smooth muscle. Br J Pharmacol 2006; 149: 1083-1091.

Laffont S, Blanquart E, Savignac M, et al. Androgen signaling negatively controls group 2 innate lymphoid cells. J Exp Med 2017; 214: 1581-1592.

Lamont KR, Tindall DJ. Androgen regulation of gene expression. Adv Cancer Res 2010; 107: 137-162.

Cephus JY, Stier MT, Fuseini H, et al. Testosterone attenuates group 2 innate lymphoid cell-mediated airway inflammation. Cell Rep 2017; 21: 2487-2499.

Mikkonen L, Pihlajamaa P, Sahu B, et al. Androgen receptor and androgen-dependent gene expression in lung. Mol Cell Endocrinol 2010; 317: 14-24.

Thurlbeck WM. Postnatal human lung growth. Thorax 1982; 37: 564-571.

Torday JS, Nielsen HC. The sex difference in fetal lung surfactant production. Exp Lung Res 1987; 12: 1-19.

Hepper PG, Shannon EA, Dornan JC. Sex differences in fetal mouth movements. Lancet 1997; 350: 1820.

Green M, Mead J, Turner JM. Variability of maximum expiratory flow-volume curves. J Appl Physiol 1974; 37: 67-74.

Doershuk CF, Fisher BJ, Matthews LW. Specific airway resistance from the perinatal period into adulthood. Alterations in childhood pulmonary disease. Am Rev Respir Dis 1974; 109: 452-457.

Pagtakhan RD, Bjelland JC, Landau LI, et al. Sex differences in growth patterns of the airways and lung parenchyma in children. J Appl Physiol Respir Environ Exerc Physiol 1984; 56: 1204-1210.

Merkus PJ, Borsboom GJ, Van Pelt W, et al. Growth of airways and air spaces in teenagers is related to sex but not to symptoms. J Appl Physiol 1993; 75: 2045-2053.

Schrader PC, Quanjer PH, Olievier ICW. Respiratory muscle force and ventilatory function in adolescents. Eur Respir J 1988; 1: 368-375.

Gibellino F, Osmanliev DP, Watson A, et al. Increase in tracheal size with age. Implications for maximal expiratory flow. Am Rev Respir Dis 1985; 132: 784-787.

Quanjer PH, Stanojevic S, Cole TJ, et al. Multi-ethnic reference values for spirometry for the 3-95-yr age range: The global lung function 2012 equations. Eur Respir J 2012; 40: 1324-1343. 
Stanojevic S, Graham BL, Cooper BG, et al. Official ERS technical standards: Global Lung Function Initiative reference values for the carbon monoxide transfer factor for Caucasians. Eur Respir J 2017; 50: 1700010.

Hall GL, Filipow N, Ruppel G, et al. Official ERS technical standard: Global Lung Function Initiative reference values for static lung volumes in individuals of European ancestry. Eur Respir J 2021; 57: 2000289.

Stanojevic S. Standardisation of lung function test interpretation: Global Lung Function Initiative. Lancet Respir 2018; 6: 10-12.

Yung JA, Fuseini H, Newcomb DC. Hormones, sex, and asthma. Ann Allergy Asthma Immunol 2018; 120: 488-494. Liptzin DR, Landau LI, Taussig LM. Sex and the lung: Observations, hypotheses, and future directions. Pediatr Pulmonol 2015; 50: 1159-1169.

Centers for Disease Control and Prevention. Most Recent Asthma Data. www.cdc.gov/asthma/most_recent data.htm Date last accessed: 5 July 2021. Date last updated: 25 March 2019.

Real FG, Svanes C, Omenaas ER, et al. Menstrual irregularity and asthma and lung function. J Allergy Clin Immunol 2007; 120: 557-564.

Postma DS. Gender differences in asthma development and progression. Gend Med 2007; 4: Suppl. 2, S133-S146.

Brenner BE, Holmes TM, Mazal B, et al. Relation between phase of the menstrual cycle and asthma presentations in the emergency department. Thorax 2005; 60: 806-809.

Canguven O, Albayrak S. Do low testosterone levels contribute to the pathogenesis of asthma? Med Hypotheses 2011; 76: 585-588.

Pereira Vega A, Sanchez Ramos JL, Maldonado Perez JA, et al. Variability in the prevalence of premenstrual asthma. Eur Respir J 2010; 35: 980-986.

Tan KS, McFarlane LC, Lipworth BJ. $\beta 2$-adrenoceptor regulation and function in female asthmatic patients receiving the oral combined contraceptive pill. Chest 1998; 113: 278-282.

Dempsey JA, Smith CA. Pathophysiology of human ventilatory control. Eur Respir J 2014; 44: 495-512.

Behan M, Kinkead R. Neuronal control of breathing: sex and stress hormones. Compr Physiol 2011; 1: 2101-2139.

Behan M, Wenninger JM. Sex steroidal hormones and respiratory control. Respir Physiol Neurobiol 2008; 164: 213-221.

Nattie E, Li A. Central chemoreceptors: Locations and functions. Compr Physiol 2012; 2: 221-254.

Joseph V, Niane LM, Bairam A. Antagonism of progesterone receptor suppresses carotid body responses to hypoxia and nicotine in rat pups. Neuroscience 2012; 207: 103-109.

Behan M, Thomas CF. Sex hormone receptors are expressed in identified respiratory motoneurons in male and female rats. Neuroscience 2005; 130: 725-734.

Popovic RM, White DP. Upper airway muscle activity in normal women: Influence of hormonal status. J App Physiol 1998; 84: 1055-1062.

Magnus-Levy H. Stoffwechsel und Nahrungsbedarf in der Schwangerschaft. Z Geburtsh. u. Gynäk 1904; 52: 116-124.

Romei M, Mauro AL, D'Angelo MG, et al. Effects of gender and posture on thoraco-abdominal kinematics during quiet breathing in healthy adults. Respir Physiol Neurobiol 2010; 172: 184-191.

White DP, Douglas NJ, Pickett CK, et al. Sexual influence on the control of breathing. J Appl Physiol Respir Environ Exerc Physiol 1983; 54: 874-879.

Jordan AS, Eckert DJ, Catcheside PG, et al. Ventilatory response to brief arousal from non-rapid eye movement sleep is greater in men than in women. Am J Respir Crit Care Med 2003; 168: 1512-1519.

Goldberg S, Ollila HM, Lin L, et al. Analysis of hypoxic and hypercapnic ventilatory response in healthy volunteers. PLOS One 2017; 12: e0168930.

Loeppky JA, Scotto P, Charlton GC, et al. Ventilation is greater in women than men, but the increase during acute altitude hypoxia is the same. Respir Physiol 2001; 125: 225-237.

Guenette JA, Diep TT, Koehle MS, et al. Acute hypoxic ventilatory response and exercise-induced arterial hypoxemia in men and women. Respir Physiol Neurobiol 2004; 143: 37-48.

Morelli C, Badr MS, Mateika JH. Ventilatory responses to carbon dioxide at low and high levels of oxygen are elevated after episodic hypoxia in men compared with women. J Appl Physiol 2004; 97: 1673-1680.

Olfert IM, Balouch J, Kleinsasser A, et al. Does gender affect human pulmonary gas exchange during exercise? J Physiol 2004; 557: 529-541.

Nozoe M, Mase K, Takashima S, et al. Measurements of chest wall volume variation during tidal breathing in the supine and lateral positions in healthy subjects. Respir Physiol Neurobiol 2014; 193: 38-42.

MacNutt MJ, De Souza MJ, Tomczak SE, et al. Resting and exercise ventilatory chemosensitivity across the menstrual cycle. J Appl Physiol 2012; 112: 737-747.

Zwillich C, Natalino M, Sutton F, et al. Effects of progesterone on chemosensitivity in normal men. J Lab Clin Med 1978; 92: 262-269.

Okita S, Kimura H, Kunitomo F, et al. Effect of chlormadinone acetate, a synthetic progesterone, on hypoxic ventilatory response in men. Jpn J Physiol 1987; 37: 137-147. 
Bayliss DA, Millhorn DE, Gallman EA, et al. Progesterone stimulates respiration through a central nervous system steroid receptor-mediated mechanism in cat. Proc Natl Acad Sci USA 1987; 84: 7788-7792.

Regensteiner JG, Woodard WD, Hagerman DD, et al. Combined effects of female hormones and metabolic rate on ventilatory drives in women. $J$ Appl Physiol 1989; 66: 808-813.

Goodland RL, Reynolds JG, McCoord AB, et al. Respiratory and electrolyte effects induced by estrogen and progesterone. Fertil Steril 1953; 4: 300-317.

Brodeur P, Mockus M, McCullough R, et al. Progesterone receptors and ventilatory stimulation by progestin. J Appl Physiol 1985; 60: 590-595.

Marques DA, De Carvalho D, Da Silva GSF, et al. Ventilatory, metabolic, and thermal responses to hypercapnia in female rats: Effects of estrous cycle, ovariectomy, and hormonal replacement. $J$ Appl Physiol 2015; 119: 61-68.

Marques DA, de Carvalho D, da Silva GSF, et al. Influence of estrous cycle hormonal fluctuations and gonada hormones on the ventilatory response to hypoxia in female rats. Pflugers Arch 2017; 469: 1277-1286.

Gonzales GF, Tapia V, Gasco M, et al. Serum testosterone levels and score of chronic mountain sickness in Peruvian men natives at 4340m. Andrologia 2011; 43: 189-195.

White DP, Schneider BK, Santen RJ, et al. Influence of testosterone on ventilation and chemosensitivity in male subjects. J Appl Physiol 1985; 59: 1452-1457. obstructive sleep apnea: A randomised, placebo-controlled trial. J Sleep Res 2013; 22: 331-336.

Koepchen HP. Über die Wirkung von Cortison und Testosteron auf die Atmung. Pflugers Arch Gesamte Physiol Menschen Tiere 1953; 257: 144-154.

Zabka AG, Mitchell GS, Behan M. Conversion from testosterone to oestradiol is required to modulate respiratory long-term facilitation in male rats. J Physiol 2006; 576: 903-912.

Pesce G, Triebner K, van der Plaat DA, et al. Low serum DHEA-S is associated with impaired lung function in women. EClinicalMedicine 2020; 23: 100389.

Real FG, Svanes C, Macsali F, et al. Hormonal factors and respiratory health in women--a review. Clin Respir J 2008; 2: Suppl. 1, 111-119.

Bäckström CT, McNeilly AS, Leask RM, et al. Pulsatile secretion of LH, FSH, prolactin, oestradiol and progesterone during the human menstrual cycle. Clin Endocrinol 1982; 17: 29-42.

balance. Am J Physiol Regul Integr Comp Physiol 2001; 280: R481-R487.

Dempsey JA, Skatrud JB. A sleep-induced apneic threshold and its consequences. Am Rev Respir Dis 1986; 133: $1163-1170$.

Hayashi K, Kawashima T, Suzuki Y. Effect of menstrual cycle phase on the ventilatory response to rising body temperature during exercise. J Appl Physiol 2012; 113: 237-245.

healthy women. Respir Physiol Neurobiol 2006; 154: 379-388.

Da Silva SB, De Sousa Ramalho Viana E, De Sousa MBC. Changes in peak expiratory flow and respiratory strength during the menstrual cycle. Respir Physiol Neurobiol 2006; 150: 211-219. 1609-1618.

Speroff L, Glass RG, Kase NG. Clinical gynecologic endocrinology and infertility. In: Mitchell C, ed. Clinical Gynecologic Endocrinology and Infertility. 6th edn. Baltimore, Lippincott Williams \& Wilkins, 1999; pp. 423-428.

8 Lindheim SR, Presser SC, Ditkoff EC, et al. A possible bimodal effect of estrogen on insulin sensitivity in postmenopausal women and the attenuating effect of added progestin. Fertil Steril 1993; 60: 664-667.

van der Plaat DA, Pereira M, Pesce G, et al. Age at menopause and lung function: a Mendelian randomisation study. Eur Respir J 2019; 54: 1802421.

1994; 7: 954-960.

Jarvis D. The European Community Respiratory Health Survey II. Eur Respir J 2002; 20: 1071-1079.

decline. Am J Respir Crit Care Med 2017; 195: 1058-1065.

Svanes C, Gomez Real F, Gislason T, et al. Association of asthma and hay fever with irregular menstruation. Thorax 2005; 60: 445-450.

Real F G, Svanes C, Björnsson EH, et al. Hormone replacement therapy, body mass index and asthma in perimenopausal women: A cross sectional survey. Thorax 2006; 61: 34-40.

Pinkerton KE, Harbaugh M, Han MLK, et al. Women and lung disease: Sex differences and global health disparities. Am J Respir Crit Care Med 2015; 192: 11-16.

Maliqueo M, Echiburú B, Crisosto N. Sex steroids modulate uterine-placental vasculature: Implications for obstetrics and neonatal outcomes. Front Physiol 2016; 7: 152. 
127 Seaborn T, Simard M, Provost PR, et al. Sex hormone metabolism in lung development and maturation. Trends Endocrinol Metab 2010; 21: 729-738.

128 Chesnutt AN. Physiology of normal pregnancy. Crit Care Clin 2004; 20: 609-615.

129 Hirnle L, Lysenko L, Gerber H, et al. Respiratory function in pregnant women. Adv Exp Med Biol 2013; 788: 153-160.

130 García-Rio F, Pino JM, Gómez L, et al. Regulation of breathing and perception of dyspnea in healthy pregnant women. Chest 1996; 110: 446-453.

131 LoMauro A, Aliverti A. Respiratory physiology of pregnancy: Physiology masterclass. Breathe 2015; 11: 297-301.

132 LoMauro A, Aliverti A, Frykholm P, et al. Adaptation of lung, chest wall, and respiratory muscles during pregnancy: Preparing for birth. J Appl Physiol 2019; 127: 1640-1650.

133 Goldsmith LT, Weiss G. Relaxin in human pregnancy. Ann N Y Acad Sci 2009; 1160: 130-135.

134 Bellemare F, Jeanneret A, Couture J. Sex differences in thoracic dimensions and configuration. Am J Respir Crit Care Med 2003; 168: 305-312.

135 Welch JF, Archiza B, Guenette JA, et al. Effect of diaphragm fatigue on subsequent exercise tolerance in healthy men and women. J Appl Physiol 2018; 125: 1987-1996.

136 Guenette JA, Romer LM, Querido JS, et al. Sex differences in exercise-induced diaphragmatic fatigue in endurance-trained athletes. J Appl Physiol 2010; 109: 35-46.

137 Archiza B, Reinhard PA, Welch JF, et al. Sex differences in diaphragmatic fatigue: Effects of hypoxia during inspiratory loading. J Physiol 2021; 599: 1319-1333.

138 O'Halloran KD. Diaphragm fatigue: Similarities and differences between sexes. J Physiol 2021; 599: 1023-1024.

139 Vowles BJ, Ahmad I, Christodoulides G. Unexpected difficult airway management in a transgender female patient. Anaesth Rep 2020; 8: 36-39.

140 Canner JK, Harfouch O, Kodadek LM, et al. Temporal trends in gender-affirming surgery among transgender patients in the United States. JAMA Surg 2018; 153: 609-616.

141 Robertson BD, Lerner BS, Collen JF, et al. The effects of transgender hormone therapy on sleep and breathing: A case series. J Clin Sleep Med 2019; 15: 1529-1533.

142 Bastir M, Godoy P, Rosas A. Common features of sexual dimorphism in the cranial airways of different human populations. Am J Phys Anthropol 2011; 146: 414-422.

143 Earl DC, Brown LK. On not knowing what we don't know to knowing what we don't know: Obstructive sleep apnea in the transgender community. J Clin Sleep Med 2019; 15: 1393-1395.

144 Lehmann Christensen L, Glintborg D, Taulbjerg Kristensen T, et al. Masculinising testosterone treatment and effects on preclinical cardiovascular disease, muscle strength and power, aggression, physical fitness and respiratory function in transgender men: Protocol for a 10-year, prospective, observational cohort study in Denmark at the Body Identity Clinic (BIC). BMJ Open 2020; 10: e045714.

145 Torres-Tamayo N, García-Martínez D, Lois Zlolniski S, et al. 3D analysis of sexual dimorphism in size, shape and breathing kinematics of human lungs. $J$ Anat 2018; 232: 227-237.

146 García-Martínez D, Torres-Tamayo N, Torres-Sanchez I, et al. Morphological and functional implications of sexual dimorphism in the human skeletal thorax. Am J Phys Anthropol 2016; 161: 467-477.

147 Deutsch MB, Buchholz D. Electronic health records and transgender patients-practical recommendations for the collection of gender identity data. J Gen Intern Med 2015; 30: 843-847.

148 Cahill S, Makadon H. Sexual orientation and gender identity data collection in clinical settings and in electronic health records: a key to ending LGBT health disparities. LGBT Health 2014; 1: 34-41.

149 Dolgin J. Transgender women on college athletic teams - the case of Lindsay Hecox. N Engl J Med 2020; 383: 2000-2002.

150 Genel M. Transgender athletes: How can they be accommodated? Curr Sports Med Rep 2017; 16: 12-13.

151 Tannenbaum C, Bekker S. Sex, gender, and sports. BMJ 2019; 364: l1120.

152 Anderson L, Knox T, Heather A. Trans-athletes in elite sport: inclusion and fairness. Emerg Top Life Sci 2019; 3: $759-762$.

153 Hilton EN, Lundberg TR. Transgender women in the female category of sport: perspectives on testosterone suppression and performance advantage. Sport Med 2021; 51: 199-214.

154 Harper J, Hirschberg AL, Jose M, et al. IOC Consensus Meeting on Sex Reassignment and Hyperandrogenism. 2015. https://stillmed.olympic.org/Documents/Commissions_PDFfiles/Medical_commission/ 2015-11_ioc_consensus_meeting_on_sex_reassignment_and_hyperandrogenism-en.pdf

155 Harper J, O'Donnell E, Sorouri Khorashad B, et al. How does hormone transition in transgender women change body composition, muscle strength and haemoglobin? Systematic review with a focus on the implications for sport participation. Br J Sports Med 2021; 55: 865-872. 